\title{
Studi Gaya Desain Eklektik pada Interior Sagoo Kitchen di Bandung
}

\author{
Lisa Levina K Jonatan ${ }^{1 *}$, Stella Sondang ${ }^{2}$ \\ ${ }^{1,2}$ Program Studi Desain Interior, Fakultas Seni Rupa dan Desain, Universitas Kristen Maranatha, \\ Bandung, Indonesia
}

\begin{abstract}
Nowadays the existence of restaurant not only rely on a tasty and delectable food, but it is also important to choose the interior design style. It is aiming to give an added value for the café. Sagoo Kitchen is one of fascinating restaurant in Bandung that wants to display the atmosphere of remembering of good old times. The way to visualize that ambience is by showing the concept of eclectic design style. Eclectic is a trend in literature, arts, design, and architecture, a merging force of style with other remarkably his characters. This café has Dutch Colonial and peranakan style from a view point of interior elements such us: floor, wall, ceiling, furniture and decorative elements.

This study uses the descriptive qualitative method, the data acquired from direct observation. Then doing the study of literature to obtain a supporting supporter related to the object case study. Based on results, there are two conclusions: First, the application of eclectic style in Sagoo Kitchen has strong correlated with the image of remembering good old times. Secondly, the concept eclectic between Dutch Colonial and Peranakan could be create a beautiful harmony, where in it there is a local image Indonesian culture.
\end{abstract}

\section{Keywords}

Dutch Colonial, eclectic, interior element, peranakan, restaurant 


\title{
Studi Gaya Desain Eklektik pada Interior Sagoo Kitchen di Bandung
}

\author{
Lisa Levina K Jonatan, Stella Sondang
}

\section{PENDAHULUAN}

Bandung terkenal sebagai kota yang menghadirkan beragam wisata kuliner kepada masyarakat. Tidak hanya keanekaragaman kuliner yang unik dan menarik tetapi juga konsep dan penyajian desain interiornya dibuat dengan berbagai inovasi yang unik. Menurut Badan Pusat Stastistik (BPS) Kota Bandung menyatakan bahwa dalam tahun 2018 tercatat lebih dari 795 restoran, café dan bar di Bandung. Perkembangan yang signifikan ini merupakan potensi yang baik dalam meningkatkan perekonomian masyarakat dan perekonomian di Bandung. Hal ini dikarenakan jumlah tenaga kerja yang bekerja di sektor ini menyerap tenaga kerja sebesar $77,85 \%$.

Fakta tersebut membuat para pemain bisnis kuliner, khususnya restoran berlomba-lomba melakukan inovasi dan meluncurkan ide-ide kreatif untuk menaikan omzet dan pengunjung agar dapat tetap bertahan. Ide kreatif yang diluncurkan pada trend restoran masa kini adalah memunculkan desain tematik yang unik dan menarik pada interior restoran. Sago kitchen merupakan salah satu restoran yang hadir dengan mengangkat tema bernostalgia dengan masa lalu yang indah atau "Remember the good old times". Ide tersebut berasal dari pemiliknya yang bernama Mulyadi Widjaja dan Marisa Imelda berkeinginan untuk menjual hidangan makanan, minuman, jajanan dengan cita rasa tempo dulu sekaligus suasana ruang interior restorannya. Hal ini tervisualisasi adanya perpaduan gaya yang dalam tata ruangnya, yaitu Dutch Colonial dan peranakkan.

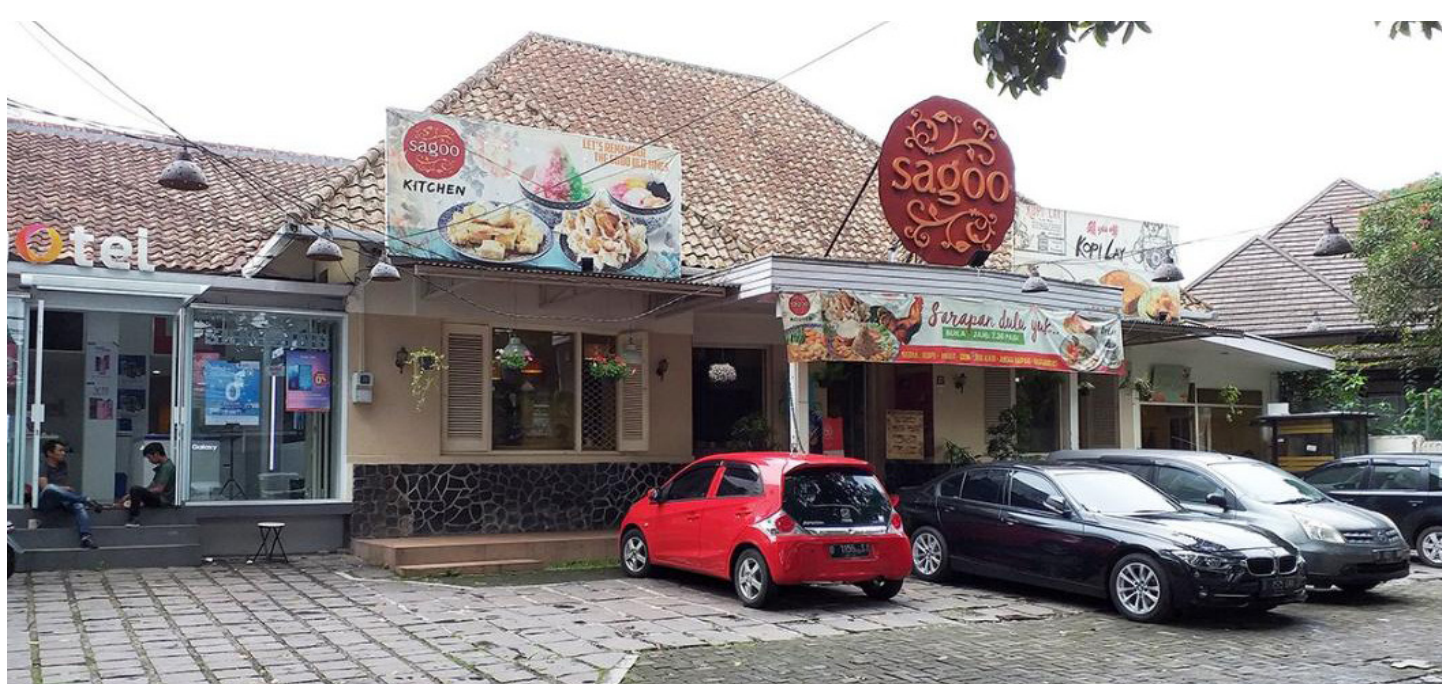

Gambar 1 Bangunan Restoran Sagoo Kitchen Restoran, JI. Trunojoyo No.27, Bandung

Sagoo Kitchen yang berlokasi di jalan Trunojoyo No.27, Bandung adalah contoh bangunan heritage di Bandung yang bergaya Dutch Colonial. Bangunan ini masih cukup terjaga originalitasnya, sekalipun beralih fungsi dari rumah tinggal menjadi restoran. Berdasarkan hasil studi literatur, gaya Dutch Colonial adalah gaya yang cukup popular di Belanda tahun 1624-1820. Gaya ini timbul dari keinginan dan usaha orang Eropa untuk menciptakan daerah jajahan seperti negara asal mereka. Pada kenyataannya desain tidak sesuai dengan bentuk asalnya karena perbedaan iklim, ketersediaan material dan perbedaan teknik di negara jajahan sehingga diperoleh bentuk modifikasi yang menyerupai desain di negara asalnya. Gaya arsitektur Dutch Colonial di Indonesia terbagi menjadi 3 yaitu Indische Empire Style, arsitektur masa transisi dan arsitektur Colonial Modern. Bangunan Sagoo kitchen termasuk dalam gaya arsitektur Indische Empire Style. Menurut Handinoto [1], indische secara harafiah berarti indis 
atau hindia. Kebudayaan indische adalah percampuran kebudayaan Eropa, Indonesia dan sedikit dari kebudayaan orang Cina peranakan. Ciri-ciri bangunan Indische Empire Style antara lain denah berbentuk simetris penuh, ditengah terdapat central room yang terdiri dari kamar tidur utama dan kamar tidur lainnya. Central room berhubungan langsung dengan teras depan dan belakang. Teras tersebut biasanya sangat luas dan diujungnya terdapat barisan kolom yang bergaya Yunani (doric, ionic dan corinthian). Area masak terpisah dengan area bangunan utama dan letaknya terdapat dibagian belakang. Jika bangunan rumah berskala besar, terdapat kebun di depan, samping dan belakang. Bahan bangunan utama menggunakan batu bata, konstruksi atap perisai, pemakaian kayu pada kusen pintu dan jendela dan pemakaian kaca belum banyak dipakai.

Pada area interior restoran, selain kental dengan nuansa Dutch Colonial dari masa bangunan, terdapat beberapa gaya lain yang ditampilkan yaitu cina dan Indonesia. Perpaduan ketiga gaya tersebut memunculkan istilah peranakan. Kata peranakan sendiri dalam Kamus Besar Bahasa Indonesia (KBBI) adalah keturunan anak negeri dengan orang asing. Desain peranakan adalah suatu gaya desain yang berkembang pada awal abad 19 hingga awal abad 20, gaya ini menggabungkan unsur budaya barat dan timur. Di Indonesia desain peranakan mengembangkan konfigurasi yang lebih formal yang bercampur dengan kultur setempat.

\section{METODE PENELITIAN}

Penelitian ini menggunakan metode penelitian deskriptif kualitatif. Tipe penelitian ini bertujuan untuk mengetahui secara detail mengenai penerapan gaya yang ada pada elemen interior Sagoo kitchen. Pengumpulan data dilakukan dengan teknik observasi dan dokumentasi yang didasarkan atas pengalaman langsung yang memungkinkan melihat dan mengamati sendiri, kemudian mencatat sesuai dengan apa yang dilihat dan dirasakan. Studi literatur dilakukan dengan cara mencari dan mencatat informasi yang memuat teori yang berhubungan dengan objek penelitian sehingga diperoleh data yang mendukung.

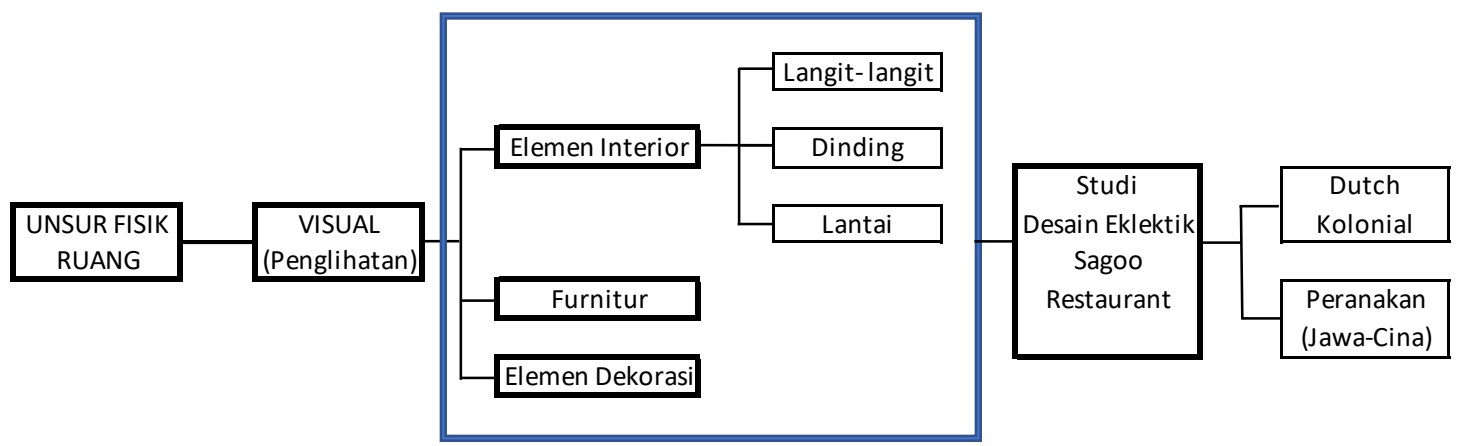

Gambar 1. Metode Penelitian Studi Eklektik Sagoo Kitchen

Berdasarkan skema tersebut maka untuk melakukan studi eklektik yang terdapat pada Sagoo Kitchen adalah dengan memahami unsur fisik ruang melalui indera penglihatan (mata). Mata merupakan indera yang paling banyak memiliki kemampuan menangkap pesan melalui bentuk visual. Kemampuan visual berkaitan dengan bentuk, warna, material, pencahayaan dan sebagainya [2]. Unsur-unsur tersebut pada sebuah ruang interior diterapkan pada elemen pembentuk ruang interior yang terdiri lantai, dinding dan langit-langit, furnitur dan elemen dekoratif.

\section{HASIL DAN ANALISA}

Bangunan Sagoo Kitchen restoran merupakan bangunan Dutch Kolonial yang mengacu pada Indische Empire Style. Tatanan simetris dan memanjang dapat dilihat dengan jelas pada organisasi ruang. Selain itu jika ditarik garis vertikal tepat dibagian tengah denah, maka akan nampak kesimetrisannya. Denah memanjang ke belakang merupakan bentuk adaptasi dengan iklim tropis agar dapat membantu pertukaran udara lebih baik. Meskipun asal mula bangunan ini adalah rumah tinggal yang kemudian dialihfungsikan sebagai restoran, namun kesan simetris dan organisasi ruang tidak berubah. Hanya terdapat beberapa penyesuaian seperti pintu-pintu dibeberapa ruang dieliminir, agar tidak mengganggu flow pengunjung dan servis serta memberi kesan terbuka dan luas. Selanjutnya, area servis yang posisi letaknya bersebrangan dengan bangunan utama diubah menjadi area makan bagi yang merokok. Hal ini menyebabkan posisi servis berubah berada di sisi samping kanan dari bangunan.

Gaya arsitektur rumah Indische Empire Style yang melekat pada bangunan restoran Sagoo Kitchen memiliki pengaruh terhadap pembentukan elemen interior ruang seperti pada lantai, dinding, langit- 
langit, kusen, pintu dan jendela. Lantai Sagoo Kitchen menggunakan material ubin dan terrazzo. Material-material ini teraplikasi pada semua area, yang membedakan hanyalah tekstur, motif dan
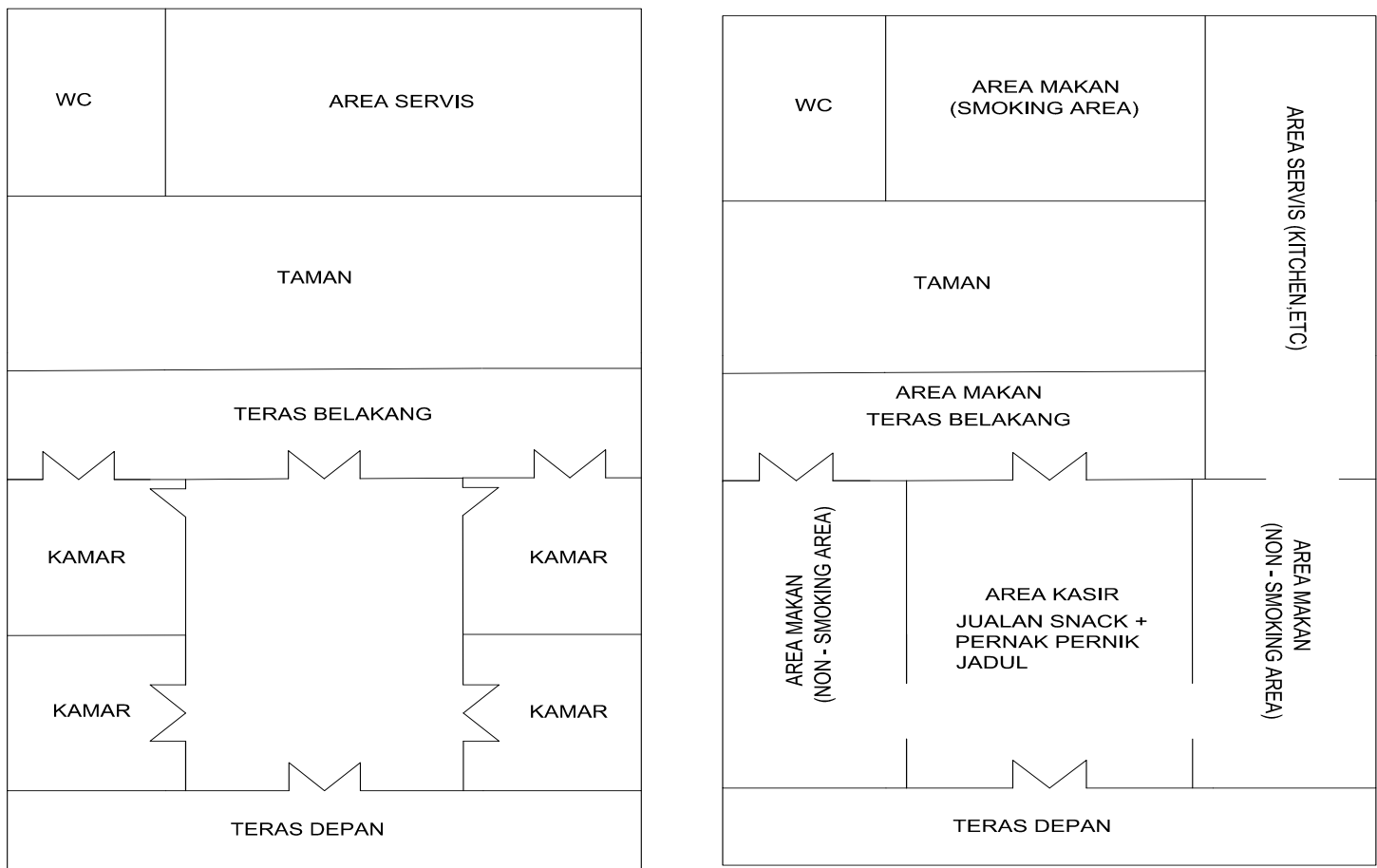

Gambar 2. Organisasi Ruang Indische Empire Style dan Re- layout Organisasi Ruang Restoran Sagoo Kitchen
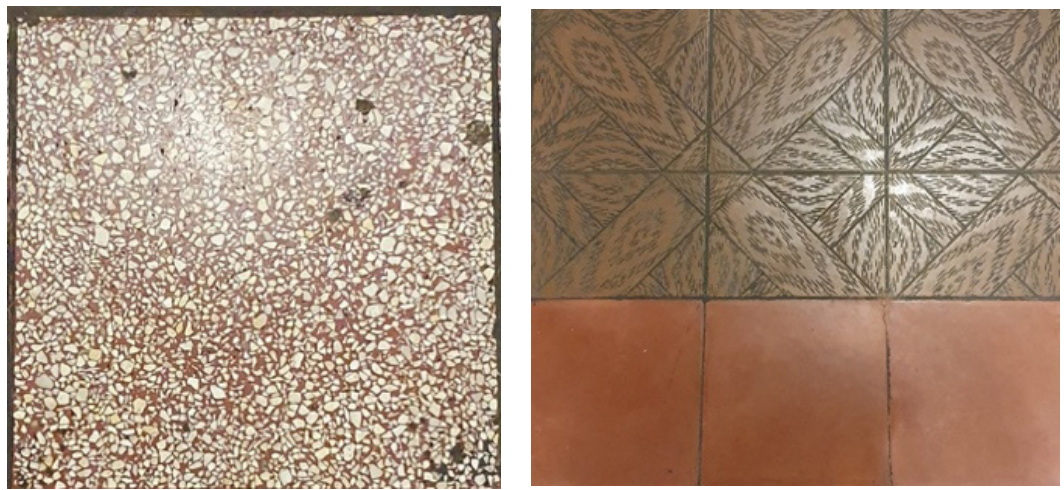

Gambar 3. Material Lantai Sagoo Kitchen

warna

Pada dinding terdapat beberapa variasi dalam penerapan, yang pertama dinding bata yang diplester dan dicat putih, putih - kekuningan dan ada beberapa tembok diberi warna merah hati sebagai aksenmyang mewakili warna cina peranakan. Kedua, dinding yang dicat putih diberi wainscoting natural kayu dan kayu difinished duco putih. Kemudian terdapat dinding yang dilapisi oleh wallpaper floral seperti area kasir dan salah satu spot area makan (non - smoking).

Di samping itu dinding - dinding diberi elemen dekoratif yang dapat memberi kesan lebih kuat terhadap tempo dulu, yaitu dengan mendisplay produk-produk makanan dan jajanan yang trend lebih dari dua dekade yang lalu sampai pada wadah untuk memasak jadul. Adapun area makan (non-smoking), tampilan produk display dekoratif yang dipasang adalah packaging-packaging dari susu, keju,bahan kue, gula dan biscuit selain itu, ada juga piring-piring bermotif floral yang banyak dipakai di era kolonial dan wadah wadah khas gaya peranakan. Berbeda dengan area makan (non-smoking), pada area makan (smoking) yang letaknya terpisah dari bangunan utama produk yang didisplay di dinding adalah tampah dan beberapa peralatan dapur.

Elevasi/ketinggian ruang dan material langit-langit pada bagian central bangunan induk masih dipertahankan menggunakan ekspos balok kayu vertikal dan horizontal. Area tersebut merupakan tempat kasir dan jajanan snack dan jualan aksesoris rumah tangga. Namun berbeda dengan penerapan material pada langit-langit area makan baik yang terdapat samping kanan dan kiri central bangunan 

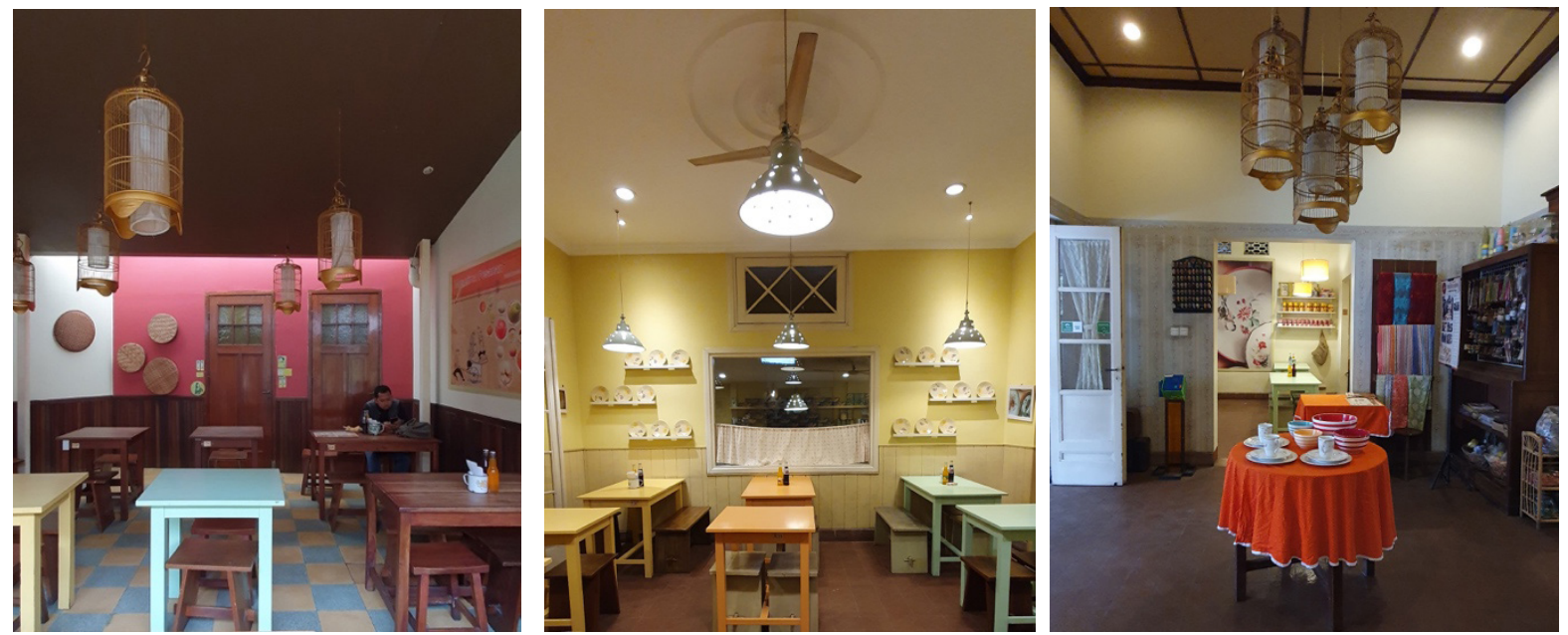

Gambar 4. Material Dinding Sagoo Kitchen, Wainscoting dan Wallpaper

maupun di belakang serta servis. Material yang digunakan adalah gypsum cat putih /coklat yang kemudian diberi aksen decorative pendant lamp. Ketinggian ruang pun mengalami penurunan dari area central.

Kusen, pintu dan jendela yang dipakai pada restoran ini masih menggunakan gaya kolonial. Adapun 2 (dua) jenis pintu yang dipakai yaitu pintu pintu swing dan pintu geser (sliding). Material pintu swing dan pintu geser adalah kombinasi kayu solid jati dengan kaca bening atau kaca patri. Kusen pintu dan jendela menggunakan material kayu solid jati. Jendela pada restoran ini ada yang masih belum berkaca hanya dibatasi dengan railing besi berwarna putih dan sebagian sudah menggunakan kaca ditambahkan denga kaca bening. Hal ini berguna untuk meningkatkan tampilan estetika restoran dari luar dan keamanan.

Furnitur yang dipilih pada Sagoo Kitchen restoran adalah perpaduan gaya tematik Dutch Colonial dan peranakan (Cina dan Indonesia). Pada area kasir, furnitur built in didesain mirip dengan tempat penyimpanan obat-obat herbal pada toko obat Cina sedangkan loose furniture seperti etalase dan rak penyimpanan jajanan makanan tempo dulu mirip seperti di toko kelontong yang ada di Indonesia.

Desain lampu dekoratif sangkar burung merupakan ciri khas dari gaya peranakan (Cina-MelayuIndonesia) memberikan aksen kuat pada tampilan desain peranakkan di area kasir. Yang menjadi unik adalah desain kasir yang menonjolkan desain peranakan ini dapat serasi dan dengan elemen bangunan Dutch Colonial seperti pintu, lantai, dan langit-langit. Hal ini juga sekaligus dapat memberikan gambaran Indonesia tempo dulu di era yang lampau. Jajanan yang ditawarkan pun merupakan jajanan yang tren di masa kecil beberapa dekade lalu memperkuat konsep "let's remember the good old times". Pada area
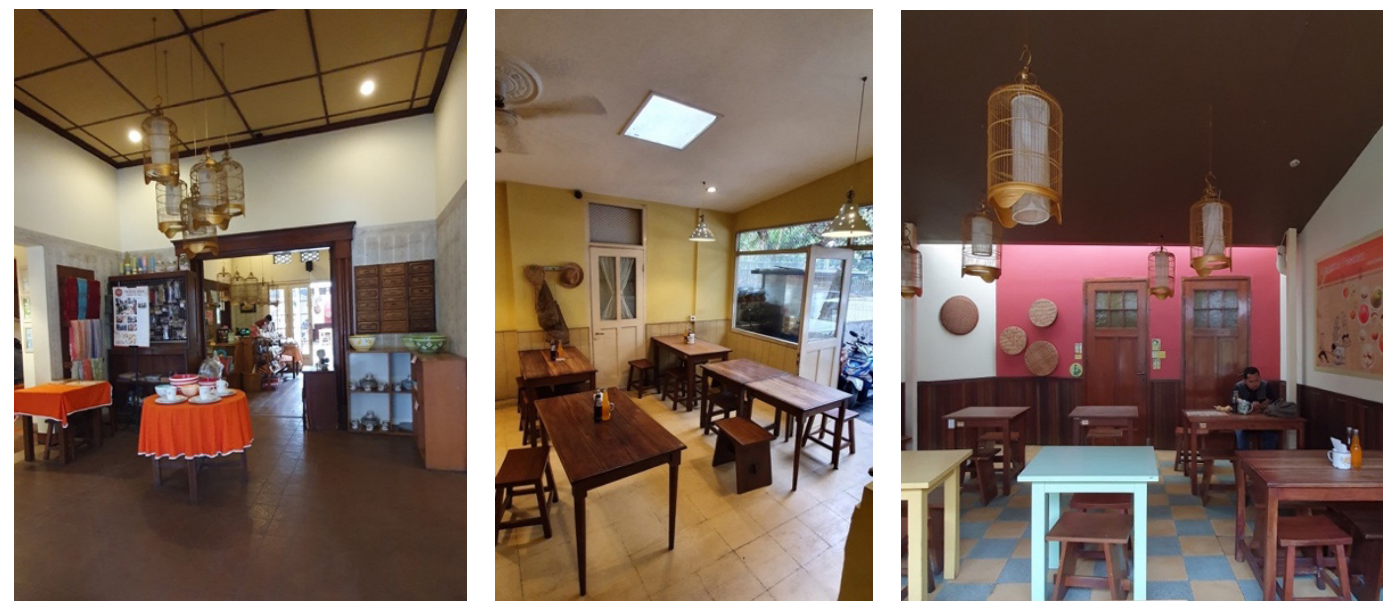

Gambar 6. Material Langit-langit di Area Kasir dan Jualan Snack- Aksesoris, Area Makan (Non- Smoking), Area Makan (Smoking)

makan baik yang berada di bangunan induk maupun sebagian di bangunan belakang terlihat seperti tipe furnitur yang ada di warung - warung Indonesia dan kedai makan yang ada di Cina lampau. Hanya ada beberapa detail bentuk dan finishing yang diadaptasi dengan era kekinian di Indonesia.

Selanjutnya berdasarkan hasil observasi di lapangan furnitur pada area servis dan area makan di teras memiliki tematik warung Indonesia dengan Dutch Colonial. Desain loose furniture di area seperti 
showcase yang ada di warung tegal/ ramesan. Material furnitur yang dipakai kayu dan kaca (agar dapat memilih makanan secara langsung atau pun dapat melihat langsung saat penyajian makanan). Set kursi dan meja yang dipilih adalah tipe furnitur Jepara-an.

Sama dengan hasil perpaduan gaya eklektik di area kasir pada area servis ini juga tematik warung dapat berintegrasi dengan gaya bangunan Dutch Colonial dan aksen warna serta elemen dekoratif peranakan (Cina Indonesia).

Meskipun tampilan gaya Dutch Colonial terkesan formal dan elegan namun jika digabung dengan gaya peranakan Cina - Indonesia menimbulkan kesan yang desain restoran Sagoo Kitchen menjadi unik, penuh dengan warna asli budaya Indonesia yang lahir dari akulturasi 3 tiga budaya ini, yaitu Belanda, Cina dan Indonesia. Konsep tematik restoran ini pun selaras dengan menu makanan yang dihidangkan berasal dari perpaduan masakan ketiga bangsa tersebut. Tak heran, Sagoo Kitchen lebih dari satu dekade dapat bertahan dan mengembangkan sayap ke beberapa tempat. Desain restoran yang ideal perlu bias bersinergis dengan konsep makanan dan branding yang disajikan sehingga dapat menciptakan pengalaman yang tidak terlupakan pada pengunjungnya.

\section{KESIMPULAN}

Gaya eklektik yang diterapkan desain interior Sagoo Kitchen adalah Dutch Colonial dan peranakkan. Perpaduan gaya ini memiliki kesesuaian dengan konsep tema restoran yang ingin mewujudkan kesan, "Remember the Good Old Times". Adapun pengaplikasian gaya Dutch Colonial dapat dilihat pada bangunan restoran yang masih merupakan bangunan rumah tinggal yang dibangun di era kolonial. Sedangkan, gaya peranakan Cina Indonesia nampak terlihat jelas pada built in furniture dan loose furniture serta elemen dekoratif seperti pada area kasir, area makan di dalam maupun di luar (teras. belakang dan servis). Kedua gaya ini dapat menjadi penggabungan yang harmoni dikarenakan di dalamnya memiliki unsur nilai budaya yang kuat dan muatan nilai local genius pada masyarakat Bandung khususnya. Desain tematik yang diterapkan pada sebuah restoran perlu memiliki identitas yang kuat agar dapat menciptakan pengalaman baru dan tak terlupakan pada pengunjungnya,

\section{DAFTAR PUSTAKA}

[1]. Handinoto \& Soehargo, P.H. Perkembangan Kota dan Arsitektur Kolonial Belanda di Malang. Yogyakarta: Diterbitkan atas kerjasama Lembaga Penelitian dan Pengabdian Kepada Masyarakat, Universitas Kristen PETRA dan penerbit Andi, 1996.

[2]. Sarihati, T. Widodo, P. \& Widihardjo Penerapan Elemen-Elemen Interior Sebagai Pembentuk Suasan Ruang Etnik Jawa Pada Restoran Boemi Joglo. Jurnal Seni Rupa Atrat, 2015; 3: 208222. 